\title{
Buspirone-associated Movement Disorder: A Literature Review
}

\author{
Jamir Pitton Rissardo, Ana Letícia Fornari Caprara \\ Department of Medicine and Department of Neurology, Federal University \\ of Santa Maria, Santa Maria, Brasil \\ Received December 29, 2019; Accepted February 17, 2020.
}

Key words: Buspirone - MJ 9022-1 - Review - Movement disorder - Drug-induced Abstract: Buspirone (BUS) belongs to the azapirone chemical class. The aim of this literature review is to evaluate the clinical epidemiological profile, pathological mechanisms, and management of BUS-associated movement disorders (MD). Relevant reports in six databases were identified and assessed by two reviewers without language restriction. A total of 25 reports containing 65 cases were assessed. The MD associated with BUS were: dyskinesia in 14 cases, 10 of akathisia, 8 of myoclonus, 6 of Parkinsonism, and 6 of dystonia. The cases not clearly defined were 7 tension, 14 incoordination, and the undefined number of dyskinesia, tics, and Parkinsonism. The mean age was 45.23 years (range: $15-74$ ). The male was the predominant sex in $60.86 \%$ and the most common BUS-indication was anxiety disorder. The mean BUS-dose was $42.16 \mathrm{mg}$ (range: 5-100). The time from the beginning of BUS administration to the MD onset was one month or less in $76 \%$. The time from BUS withdrawal to complete recovery was within one month in $87.5 \%$. The most common management was BUS withdrawal. In 16 patients the follow-up was reported: 14 had a full recovery, but in two (1 dyskinesia +1 dystonia) the symptoms continued after the BUS withdrawal. MD associated with BUS were scarcely reported in the literature. Moreover, in the majority of cases, no clear description of the clinical profile, neurological examination, or the time data of the movement disorder onset and recovery were given.

Mailing Address: Dr. Jamir Pitton Rissardo, Rua Roraima, Santa Maria, Rio Grande do Sul, Brasil; Phone: (55) (55) 334729 08; e-mail: jamirrissardo@gmail.com 


\section{Introduction}

Buspirone (BUS) belongs to the azapirone chemical class. The chemical studies of this compound began in the 1960s, in which Mead Johnson and Company was attempting to develop an antipsychotic drug with a selective interaction to dopamine receptors and a lesser number of side effects (Howland, 2015). In rhesus monkeys during the 1970s, it was noted that the BUS can lead to hypoactivity controlling aggressive behaviour but it was not effective as antipsychotics (Tompins et al., 1980); further animal studies confirmed these results (Loane and Politis, 2012). The approval by the Food and Drug Administration (FDA) in 1986 was done after one large clinical trial with more than nine hundred patients showing the safety and efficacy of the medication when compared to alprazolam, clorazepate, diazepam, and lorazepam to the management of anxiety disorders (Newton et al., 1986). At the end of the 1980s, more than thirty countries had approved BUS for clinical use including the United Kingdom (Taylor, 1988). It is worthy of mentioning that even though clinically BUS may resemble benzodiazepines, it does not have an affinity for benzodiazepine-GABA receptor complex (Loane and Politis, 2012) or has physical dependence (Griffith et al., 1986).

The azapirone medication is approved by the FDA to anxiety disorders, mainly generalized anxiety disorder, or the short-term relief of the symptoms of anxiety. In addition, BUS is used off-label for bruxism, depression (often in combination with other agents), neuropathic pain, posttraumatic stress syndrome, smoking cessation, substance abuse, and tardive dyskinesia (Howland, 2015; Wilson and Tripp, 2019).

The main mechanism of action of BUS is the partial agonism to serotonin $5 \mathrm{HT} 1 \mathrm{~A}$ auto and heteroreceptors decreasing the adenylate cyclase in the raphe nuclei, cortex, and hippocampus (Eison and Temple, 1986). The interaction with this receptor probably explains the majority of the therapeutic benefits of the medication. Also, it has an antagonism to dopamine receptors, which may be involved with the rare side effects of the medication in predisposed individuals (McMillen et al., 1983). The bioavailability is less than five percent, and more than half of the drug is metabolized to the 1-(2-pyrimidinyl) piperazine (1-PP) by the cytochrome P450 3A4. The 1-PP is believed to have a greater affinity to the adrenergic $\alpha 2 \mathrm{~A}$ receptors leading to the disinhibition of the central noradrenergic system (Engberg, 1989) (Figure 1) (McMillen et al., 1983; Eison and Temple, 1986; Taylor, 1988; Wilson and Tripp, 2019).

The most common side effect related with the use of BUS is dizziness, other adverse events that occurred in more than one percent of the individuals are nausea, headache, nervousness, blurred vision, confusion, diarrhea, insomnia, myalgia, numbness, paresthesias, rash, tremor, weakness, nonspecific chest pain (Taylor, 1988; Bristol-Myers Squibb Company, 2001). The only absolute contraindication is hypersensitivity to the drug (Bristol-Myers Squibb Company, 2001). During the clinical trials to the approval of the BUS, the most frequently reported movement disorders related to this drug were incoordination and tremor (Newton et al., 


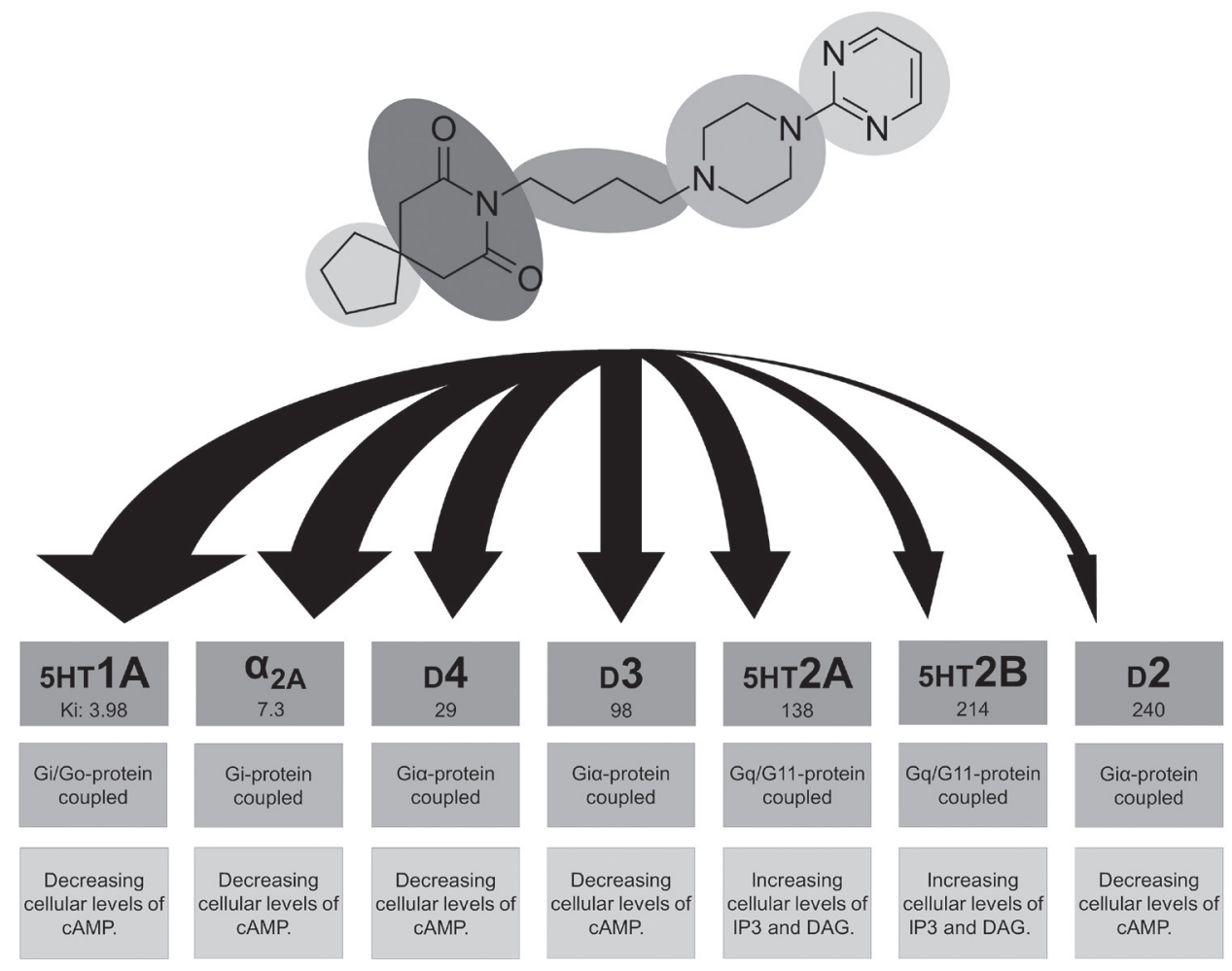

Figure 1 - Skeletal formula and pharmacodynamics of buspirone (BUS). The size of the arrow is inversely proportionally to the $\mathrm{Ki}$ (smaller the value stronger is the drug binds to the site). BUS acts as an agonist of the serotonin receptors $(5 \mathrm{HT1} A, 2 \mathrm{~A}$, and $2 \mathrm{~B})$ and antagonists of adrenergic $(\alpha 2 \mathrm{~A})$ and dopamine receptors (D2, 3, 4).

1986). Other abnormal movements were rarely reported and only registered after the post-marketing experience, these are struggling to diagnosis and when present significantly affect the patients' quality of life. In this way, the aim of this literature review is to evaluate the clinical epidemiological profile, pathological mechanisms, and management of buspirone-associated movement disorders.

\section{Methods}

\section{Search strategy}

We searched six databases in an attempt to locate all existing reports on the movement disorders secondary to buspirone treatment published between 1985 and 2019 in electronic form. Excerpta Medica (Embase), Google Scholar, Latin American and Caribbean Health Sciences Literature (Lilacs), Medline, Scientific Electronic Library Online (Scielo), and ScienceDirect were searched. Search terms were "Parkinsonism, dyskinesia, chorea, ballism, akathisia, myoclonus, dystonia, 
Table 1 - FreeText and MeSH search terms in the US National Library of Medicine

\begin{tabular}{|c|c|c|}
\hline Category & Search terms & Results \\
\hline Parkinsonism & 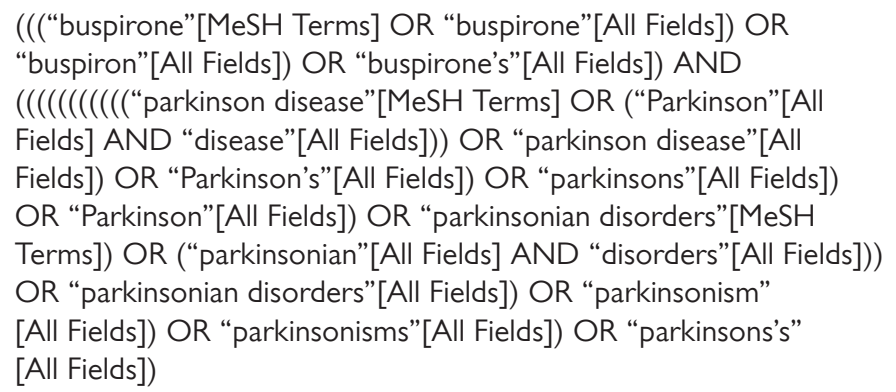 & 58 \\
\hline Tics & $\begin{array}{l}\text { ((“"buspirone”[MeSH Terms] OR "buspirone"[All Fields]) } \\
\text { OR “buspiron”[All Fields]) OR “buspirone's"[All Fields]) } \\
\text { AND (“TIC"[Dournal] OR “TIC"[All Fields]) }\end{array}$ & 7 \\
\hline Dyskinesia & $\begin{array}{l}\text { ((("buspirone"[MeSH Terms] OR "buspirone”[All Fields]) } \\
\text { OR “buspiron”[All Fields]) OR “buspirone's"[All Fields]) } \\
\text { AND ((((“dyskinesiae”[All Fields] OR “dyskinesias”[MeSH Terms]) } \\
\text { OR “dyskinesias”[All Fields]) OR “dyskinesia”[All Fields]) } \\
\text { OR “dyskinesis"[All Fields]) }\end{array}$ & 148 \\
\hline Dystonia & 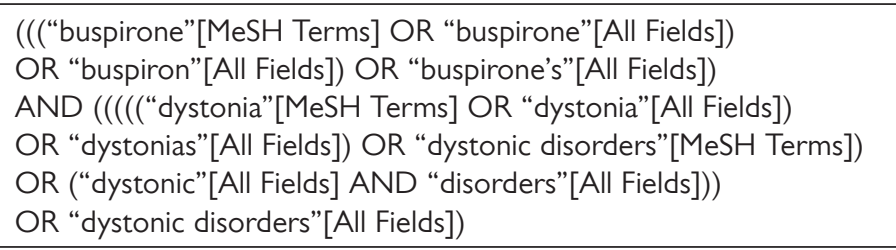 & 16 \\
\hline Stuttering & 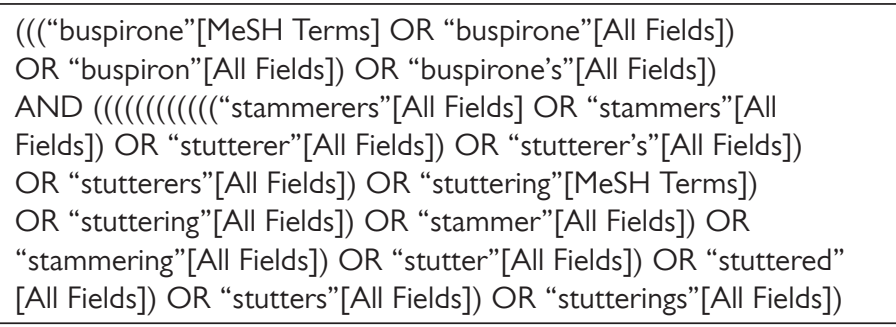 & 0 \\
\hline Myoclonus & $\begin{array}{l}\text { (((“buspirone”[MeSH Terms] OR “buspirone”[All Fields]) } \\
\text { OR “buspiron”[All Fields]) OR “buspirone's"[All Fields]) } \\
\text { AND (((“myoclonias”[All Fields] OR “myoclonus"[MeSH Terms]) } \\
\text { OR “myoclonus”[All Fields]) OR “myoclonia”[All Fields]) }\end{array}$ & 13 \\
\hline $\begin{array}{l}\text { Restless legs } \\
\text { syndrome }\end{array}$ & 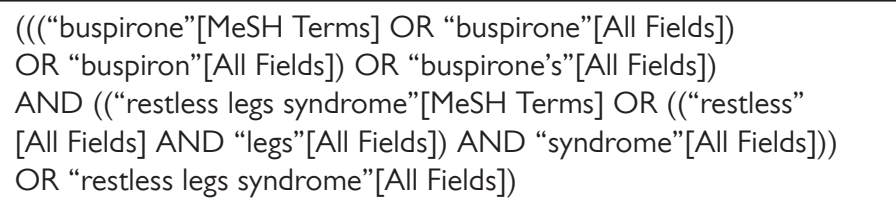 & 1 \\
\hline
\end{tabular}




\begin{tabular}{|c|c|c|}
\hline Akathisia & 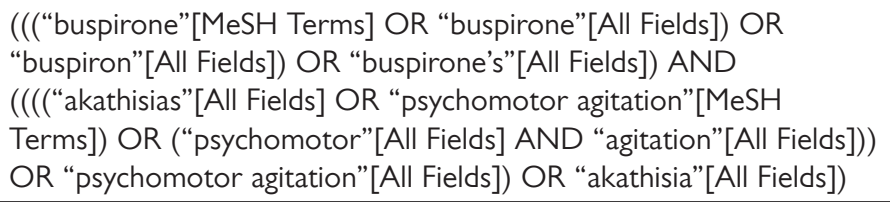 & 33 \\
\hline Tremor & $\begin{array}{l}\text { ((("buspirone”[MeSH Terms] OR "buspirone"[All Fields]) } \\
\text { OR “buspiron”[All Fields]) OR “buspirone's"[All Fields]) } \\
\text { AND ((((“"trembling”[All Fields] OR “tremor”[MeSH Terms]) } \\
\text { OR “tremor”[All Fields]) OR “tremors”[All Fields]) } \\
\text { OR “tremoring”[All Fields]) OR “tremorous”[All Fields]) }\end{array}$ & 17 \\
\hline Chorea & $\begin{array}{l}\text { (((“buspirone”[MeSH Terms] OR “buspirone"[All Fields]) } \\
\text { OR “buspiron"[All Fields]) OR "buspirone's"[All Fields]) } \\
\text { AND ((“chorea”[MeSH Terms] OR “chorea”[All Fields]) } \\
\text { OR “choreas”[All Fields]) }\end{array}$ & 8 \\
\hline Restlessness & 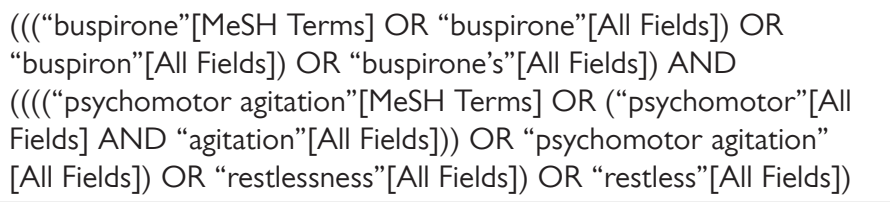 & 32 \\
\hline Ataxia & $\begin{array}{l}\text { (((“buspirone”[MeSH Terms] OR “buspirone”[All Fields]) } \\
\text { OR “buspiron”[All Fields]) OR “buspirone's"[All Fields]) } \\
\text { AND ((“ataxia”[MeSH Terms] OR “ataxia”[All Fields]) } \\
\text { OR “ataxias”[All Fields]) }\end{array}$ & 36 \\
\hline Ballism & $\begin{array}{l}(((\text { "buspirone”[MeSH Terms] OR “buspirone”[All Fields]) } \\
\text { OR “buspiron”[All Fields]) OR “buspirone's”[All Fields]) } \\
\text { AND ((“dyskinesias”[MeSH Terms] OR “dyskinesias”[All Fields]) } \\
\text { OR “ballism”[All Fields]) }\end{array}$ & 140 \\
\hline Hyperkinetic & $\begin{array}{l}\text { ((“"buspirone"[MeSH Terms] OR “buspirone”[All Fields]) } \\
\text { OR “buspiron”[All Fields]) OR “buspirone's"[All Fields]) } \\
\text { AND (“hyperkinetic”[All Fields] OR “hyperkinetics”[All Fields]) }\end{array}$ & 0 \\
\hline Hypokinetic & $\begin{array}{l}\text { (((“buspirone"[MeSH Terms] OR “buspirone”[All Fields]) } \\
\text { OR “buspiron”[All Fields]) OR “buspirone's"[All Fields]) } \\
\text { AND ((“hypokinesia”[MeSH Terms] OR “hypokinesia”[All Fields]) } \\
\text { OR “hypokinetic"[All Fields]) }\end{array}$ & 1 \\
\hline Bradykinesia & 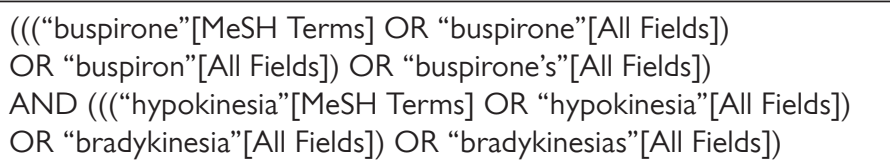 & 1 \\
\hline $\begin{array}{l}\text { Movement } \\
\text { disorder }\end{array}$ & 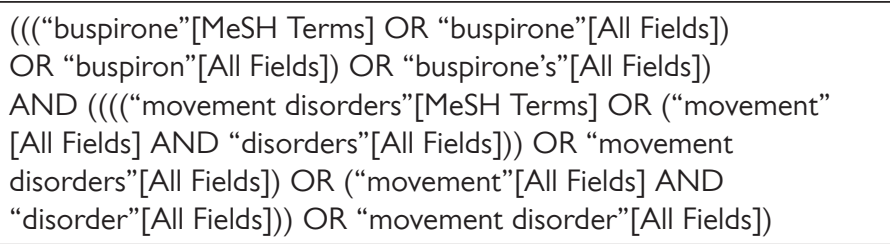 & 93 \\
\hline Total & & 604 \\
\hline
\end{tabular}


restless legs syndrome, tremor, tic, restlessness, ataxia, hyperkinetic, hypokinetic, bradykinesia, movement disorder". These terms were combined with "buspirone, MJ 9022-1" (Table 1).

\section{Inclusion and exclusion criteria}

Case reports, case series, original articles, letters to the editor, bulletins, and poster presentations published from 1985 to 2019 were included in this review with no language restriction. The two authors independently screened the titles and abstracts of all papers found from the initial search. Disagreements between the authors were resolved through discussion.

We excluded cases that the abnormal movement was not worsened or related to buspirone. Cases that had more than one factor contributing to the movement disorder were evaluated according to the probability of the event occurrence based on the Naranjo algorithm. Also, cases that were not accessible by electronic methods including direct request to the authors of the study by email were excluded. Reports that the individuals only developed tremor or ataxia after buspirone use were also not included.

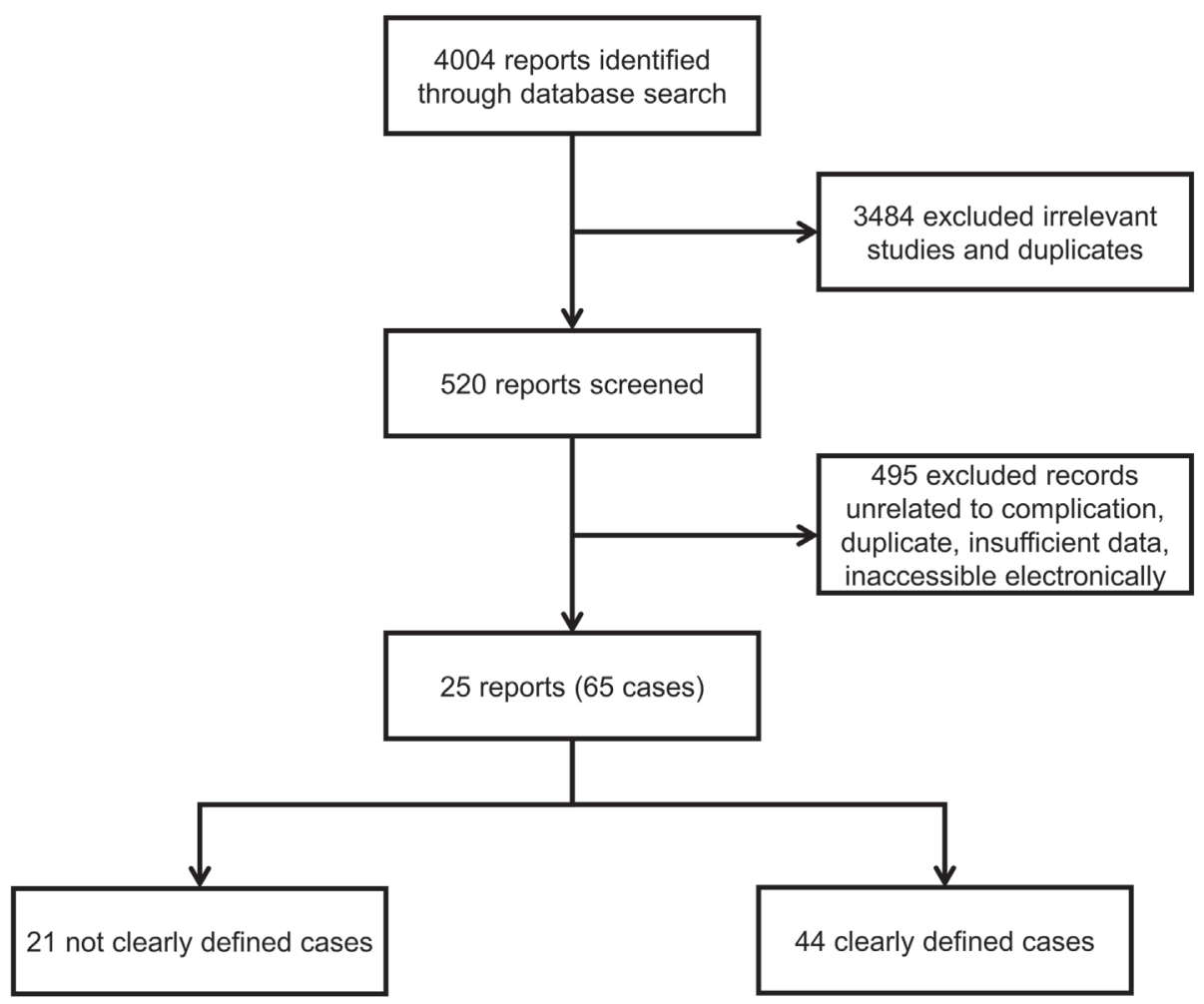

Figure 2 - Flow chart of the screening process. 


\section{Data extraction}

A total of 4,004 papers were found; 3,484 were irrelevant (Figure 2). When provided, we extracted author, department, year of publication, country of occurrence, number of patients affected, buspirone indication including off-label uses, time from first buspirone-dose till movement disorder onset, time from buspirone withdrawal to symptoms improvement, patient's status at follow-up, and important findings of clinical history and management. A large percentage of the reports did not describe the management and even the onset and recovery times of movement disorder. The data were extracted by two independent authors, double-checked to ensure matching, and organized by whether the movement disorder was a side effect of the buspirone use.

\section{Statistical analysis}

Categorical variables were represented as proportions; continuous variables were represented as mean, standard deviations (SD), median, and range.

\section{Definitions}

The clinical characteristics and definitions of the movement disorders such as Parkinsonism, dyskinesia, chorea, ballism, akathisia, myoclonus, dystonia, restless legs syndrome, tremor, and tic were obtained from the reference Jankovic and Tolosa (2007). The clinical diagnosis for the psychiatric conditions was obtained from the Diagnostic and Statistical Manual of Mental Disorders (DSM-5) (American Psychiatric Association, 2013). The Naranjo algorithm was used for determining the likelihood of whether an adverse drug reaction was actually due to the drug rather than the result of other factors (Naranjo et al., 1981).

\section{Results}

For the years 1985 and 2019, a total of 25 reports containing 65 cases from eight countries who developed a movement disorder secondary to buspirone were reported (Table 2) (Hammerstad et al., 1986; Ludwig et al., 1986; Newton et al., 1986; Liegghio et al., 1988; Patterson, 1988; Ritchie et al., 1988; Strauss, 1988; Lydiard, 1989; Boylan, 1990; Brody et al., 1990; Metz, 1990; Rock, 1990; Goff et al., 1991; Kleedorfer et al., 1991; Goldberg and Huk, 1992; Naber et al., 1992; LeWitt et al., 1993; Pranzatelli et al., 1993; Bonifati et al., 1994; Coulter and Pillans, 1995; Poyurovsky and Weizman, 1997; Manos, 2000; Clay and Adams, 2003; Mejia and Jankovic, 2005; Scholtissen et al., 2006). Figure 3 shows the number of reports associated with movement disorders and BUS throughout time. The origin was North American in 56, European 6, Asian 2, and 1 Australian. The movement disorders associated with BUS were 14 dyskinesias, 10 akathisia, 8 myoclonus, 6 Parkinsonism, and 6 dystonia. The cases not clearly defined were 7 tension, 14 incoordination, and the undefined number of dyskinesia, tics, and Parkinsonism. 


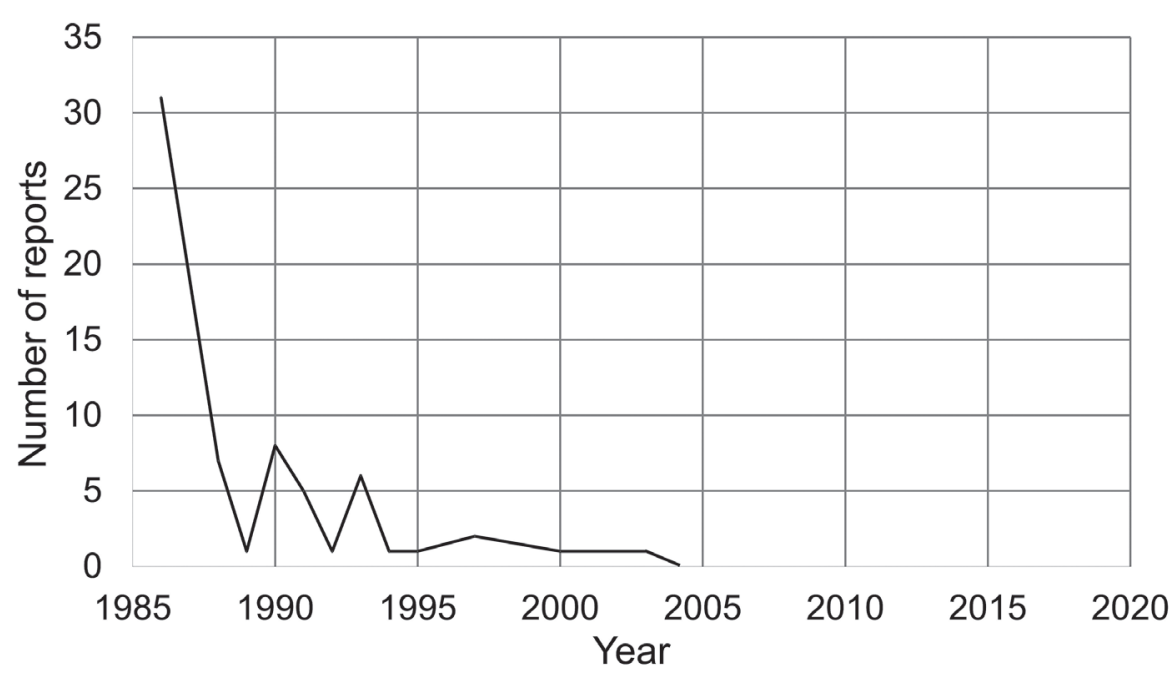

Figure 3 - Graphic showing the number of clinical reports of buspirone-associated movement disorder from 1985 to 2019.

The following data will be only about the clearly defined group, which includes 44 individuals. The mean and median age were respectively 45.23 (SD 16.82) and 52 years (age range: $15-74$ years). The male was the predominant sex in $60.86 \%$ $(14 / 23)$. The indications of BUS were in decrescent order anxiety disorders in 39.39\% (13/33), Parkinson's disease (5), schizophrenia (5), myoclonus (4), panic disorders (3), akathisia (2), and dystonia (1). The mean and median BUS-dose were respectively 42.16 (SD 29.23) and $30 \mathrm{mg}$ (dose range: 5-100 mg); 1 at $5 \mathrm{mg}$, 1 at $10 \mathrm{mg}, 5$ at $15 \mathrm{mg}, 4$ at $20 \mathrm{mg}, 2$ at $25 \mathrm{mg}, 3$ at $30 \mathrm{mg}, 3$ at $40 \mathrm{mg}, 4$ at $60 \mathrm{mg}$, 1 at $65 \mathrm{mg}, 2$ at $70 \mathrm{mg}, 1$ at $90 \mathrm{mg}, 3$ at $100 \mathrm{mg}$.

The time from the beginning of BUS administration to the movement disorder onset was defined by 30 individuals, the mean and median onset time were 4.6 (SD 4.6) and 4 weeks (onset range: 1 day-21 weeks). The onset time was within one month in $76 \%$ of the cases. The time from BUS withdrawal to complete recovery was defined in 8 individuals and was within one month in 7 cases. A moderate linear correlation ( $r$ : 0.4550) between the time from BUS start to movement disorder onset and BUS-dose was found.

In almost all cases that the management was reported, the BUS was withdrawn after the onset of movement disorder. Other options were BUS-dose reduction, maintenance even with the presence of the abnormal movement, and the start of other medications such as benzodiazepines, diphenhydramine, benztropine, trihexyphenidyl, baclofen, and carbidopa/levodopa. In some cases, there was a possible interaction between the medications and other drugs were also withdrawal 
together with BUS. In 16 patients the follow-up was reported; 14 had a full recovery, but in two (1 dyskinesia +1 dystonia) the symptoms continued after the BUS withdrawal.

\section{Discussion}

General

Movement disorders associated with buspirone (BUS) were scarcely reported in the literature. It is worth mentioning that buspirone hydrochloride was the $80^{\text {th }}$ most used medication with more than ten million prescriptions in 2016 (ClinCalc, 2019). In addition, the majority of the reports occurred due to possible interaction with other medications; the use of BUS and haloperidol is one example of that, which when used together, an increasing number of dyskinesias was shown, that were first thought to be related with BUS alone (Goff et al., 1991). However, clear analyses revealed that the increase in the concentration of haloperidol by BUS may be the best explanation. Another example is the interaction with fluoxetine since both can increase serotonin levels. There is a greater probability of serotoninergic syndrome when they are used together (Coulter and Pillans, 1995).

The cases that only reported ataxia and tremor were excluded from the analysis to limit the number of references and due to different reporting purposes. The incidence of these two abnormal movements with BUS is approximately one percent (Taylor, 1988). The complaints about tremors occurred since the first clinical trials; the ataxia was only post-marketing, but the trials described incoordination in their side effect lists (Newton et al., 1986). The data of Newton et al. (1986) in Table 2 were included because some reports like Boylan (1990) described that they represent dystonic cases.

Based on the cases reported in Table 2, we can describe a hypothetical case report. A North American middle-aged male presented to his psychiatrist due to the worsening of anxiety. The physician started BUS treatment with progressive increase till 10-15 mg tid. One month after in the follow-up, the individual complained of abnormal movements, and he was diagnosed with dyskinesia. BUS was withdrawn, and within one month the individual had a full recovery of the motor symptoms.

Figure 4 shows a resume of the mechanisms to explain the BUS-use for neuropathic pain (dorsal horn) and dyskinesia (dorsal raphe) (Shireen, 2016; Haleem et al., 2018). We believe that some of the movement disorders can be explained by the same process as represented by the treatment of these two pathologies. Herein, we would like to discuss some of the movement disorders in subtopics to give a better comprehension of the data.

\section{Dyskinesias (DKN)}

This was the most common reported movement disorder secondary to BUS, but the description of the cases was poor with all reports missing at least one important information. The age of the affected individuals was higher when compared to the 
14) Prague Medical Report / Vol. 121 (2020) No. 1, p. 5-24

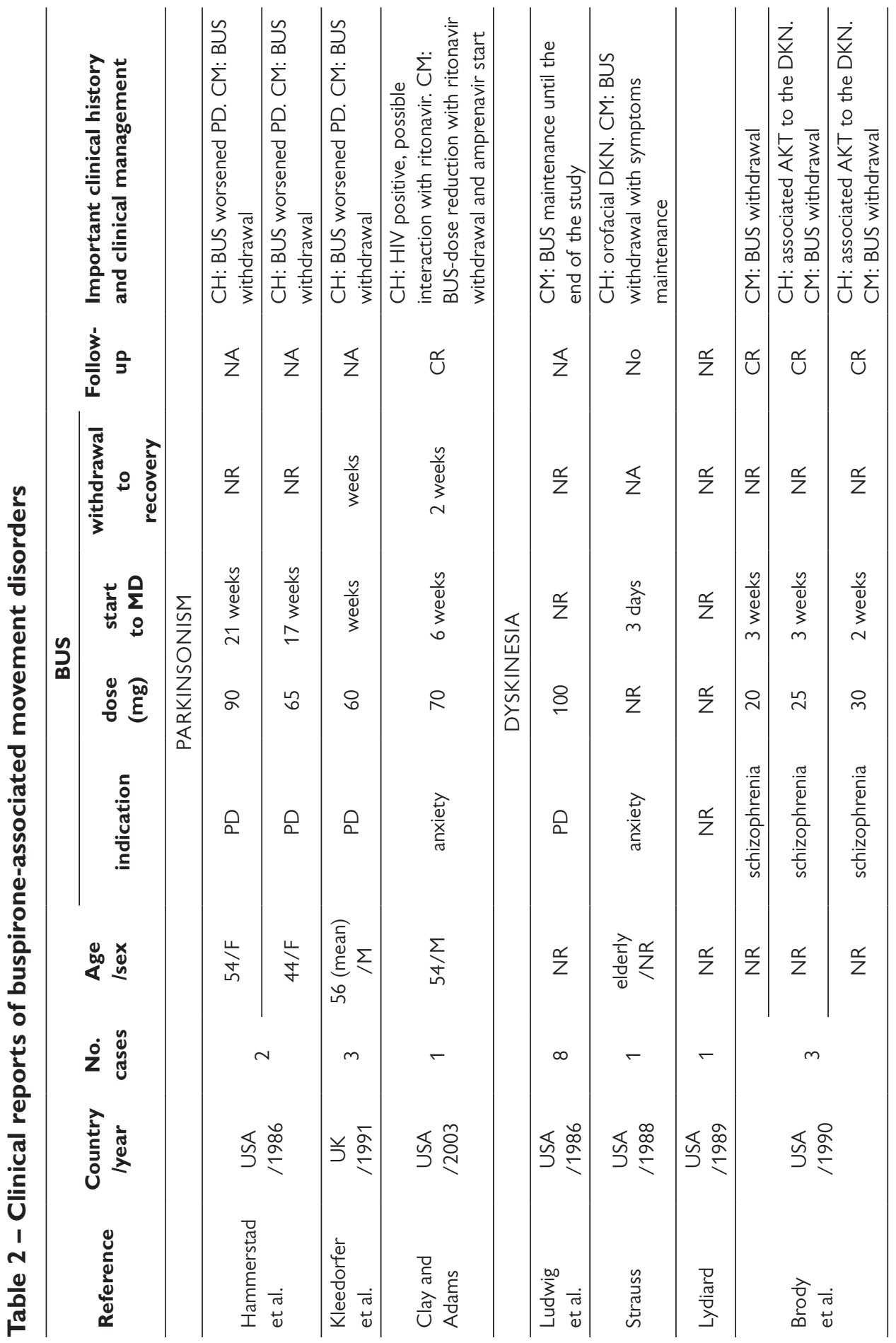




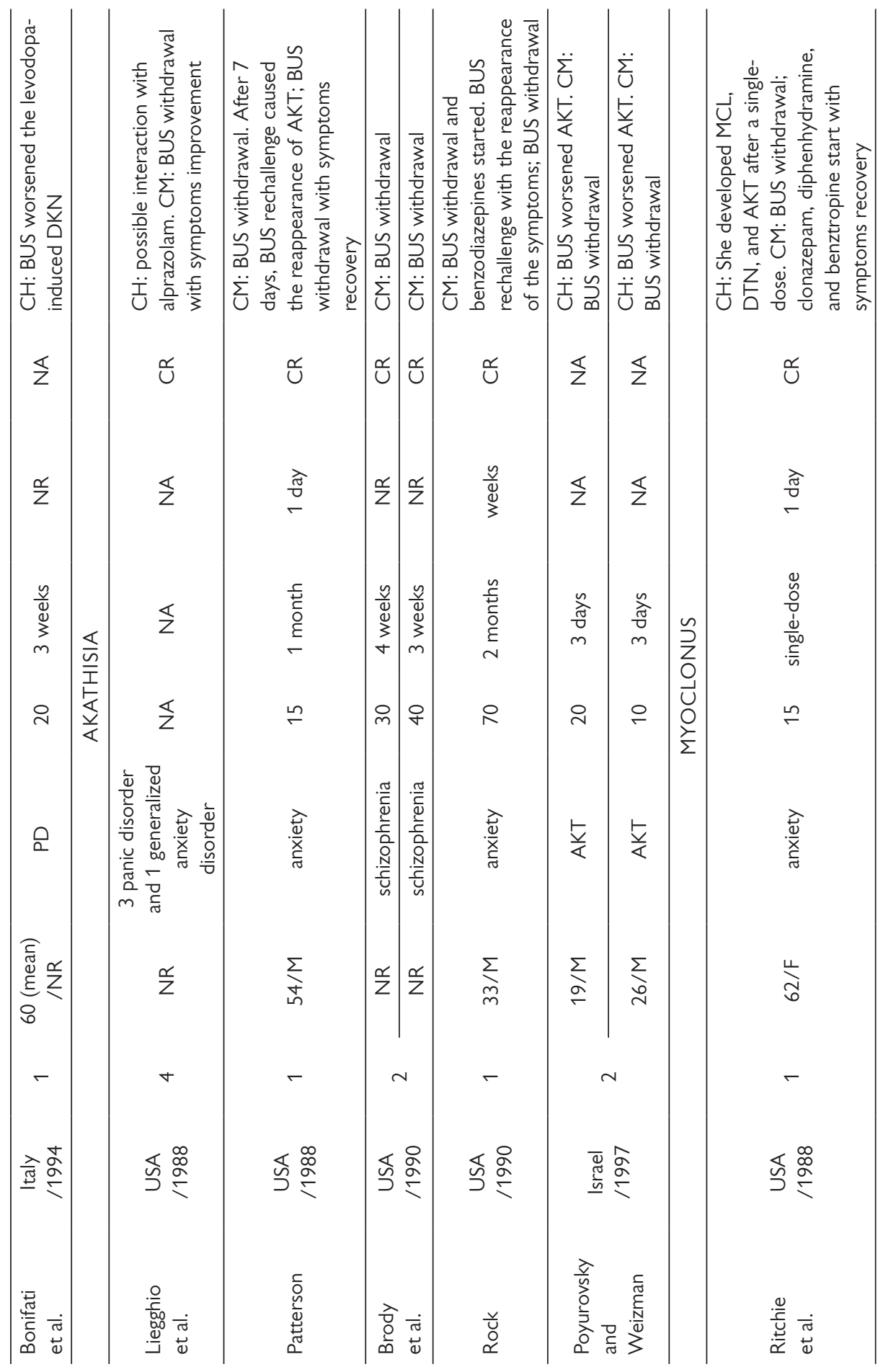


16) Prague Medical Report / Vol. 121 (2020) No. 1, p. 5-24

\begin{tabular}{|c|c|c|c|c|c|c|c|c|}
\hline 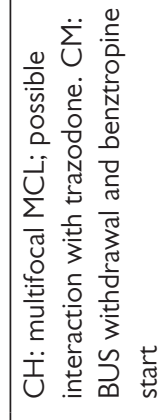 & 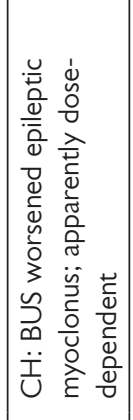 & 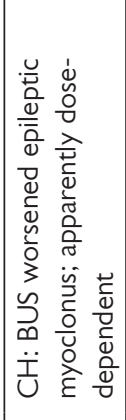 & 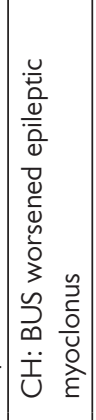 & 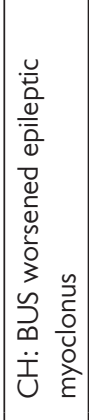 & 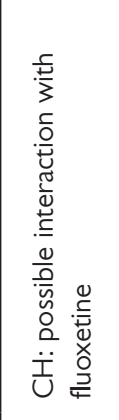 & 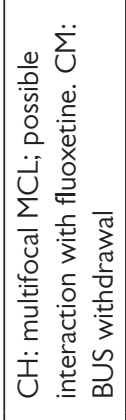 & & 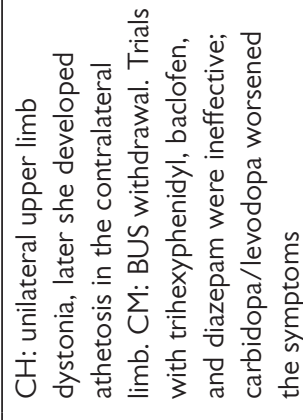 \\
\hline 品 & 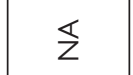 & 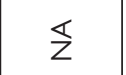 & 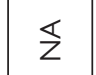 & $\S$ & $\stackrel{\alpha}{Z}$ & 品 & & $\stackrel{\mathscr{U}}{\mathrm{U}}$ \\
\hline 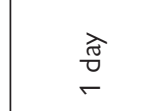 & ¿ & $\overleftarrow{z}$ & $\overleftarrow{z}$ & 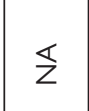 & $\stackrel{\alpha}{z}$ & $\begin{array}{l}\stackrel{n}{\widehat{\sigma}} \\
\stackrel{\sim}{v}\end{array}$ & & 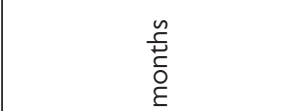 \\
\hline 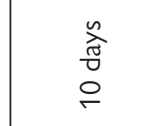 & 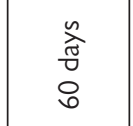 & 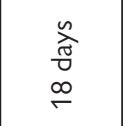 & $\begin{array}{l}\stackrel{n}{\hat{\jmath}} \\
m \\
m\end{array}$ & $\begin{array}{l}\stackrel{n}{\widehat{\widehat{O}}} \\
\stackrel{0}{r} \\
m\end{array}$ & $\frac{\alpha}{z}$ & $\begin{array}{l}\frac{\tilde{y}}{\tilde{\Xi}} \\
3 \\
3 \\
\sigma\end{array}$ & $\lesssim$ & 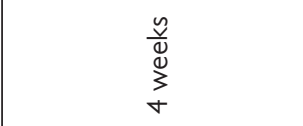 \\
\hline$\stackrel{\llcorner}{\sim}$ & $\stackrel{\stackrel{n}{r}}{ }$ & $\stackrel{\sim}{\sim}$ & $\stackrel{\Perp n}{\sim}$ & เn & $\stackrel{\alpha}{Z}$ & ㅇ & 点 & 우 \\
\hline 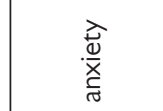 & $\vec{U}$ & $\frac{\vec{U}}{\Sigma}$ & $\frac{\vec{U}}{\Sigma}$ & $\frac{\vec{U}}{\Sigma}$ & 版 & $\begin{array}{l}\overrightarrow{\vec{d}} \\
\stackrel{\vec{x}}{\bar{d}}\end{array}$ & & 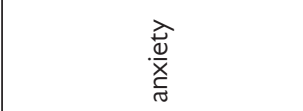 \\
\hline$\sum_{\underset{\perp}{\perp}}$ & $\underset{\Sigma}{\stackrel{\Sigma}{\sim}}$ & $\underset{\infty}{\infty}$ & $\underset{⿱}{\stackrel{2}{\sigma}}$ & $\stackrel{\Perp}{\stackrel{\Delta}{~}}$ & 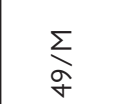 & 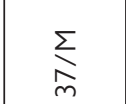 & & $\underset{⿱ 乛}{\stackrel{u}{f}}$ \\
\hline$r$ & & $\sigma$ & & & - & $r$ & & $r$ \\
\hline 岁余 & & 范 & & & 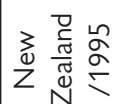 & 『্ & & 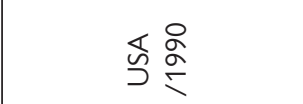 \\
\hline 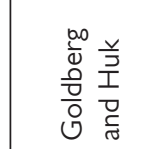 & & 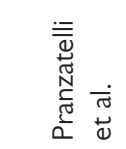 & & & 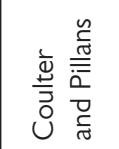 & 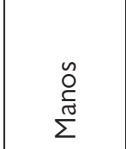 & & $\frac{\sqrt[c]{0}}{\grave{D}}$ \\
\hline
\end{tabular}




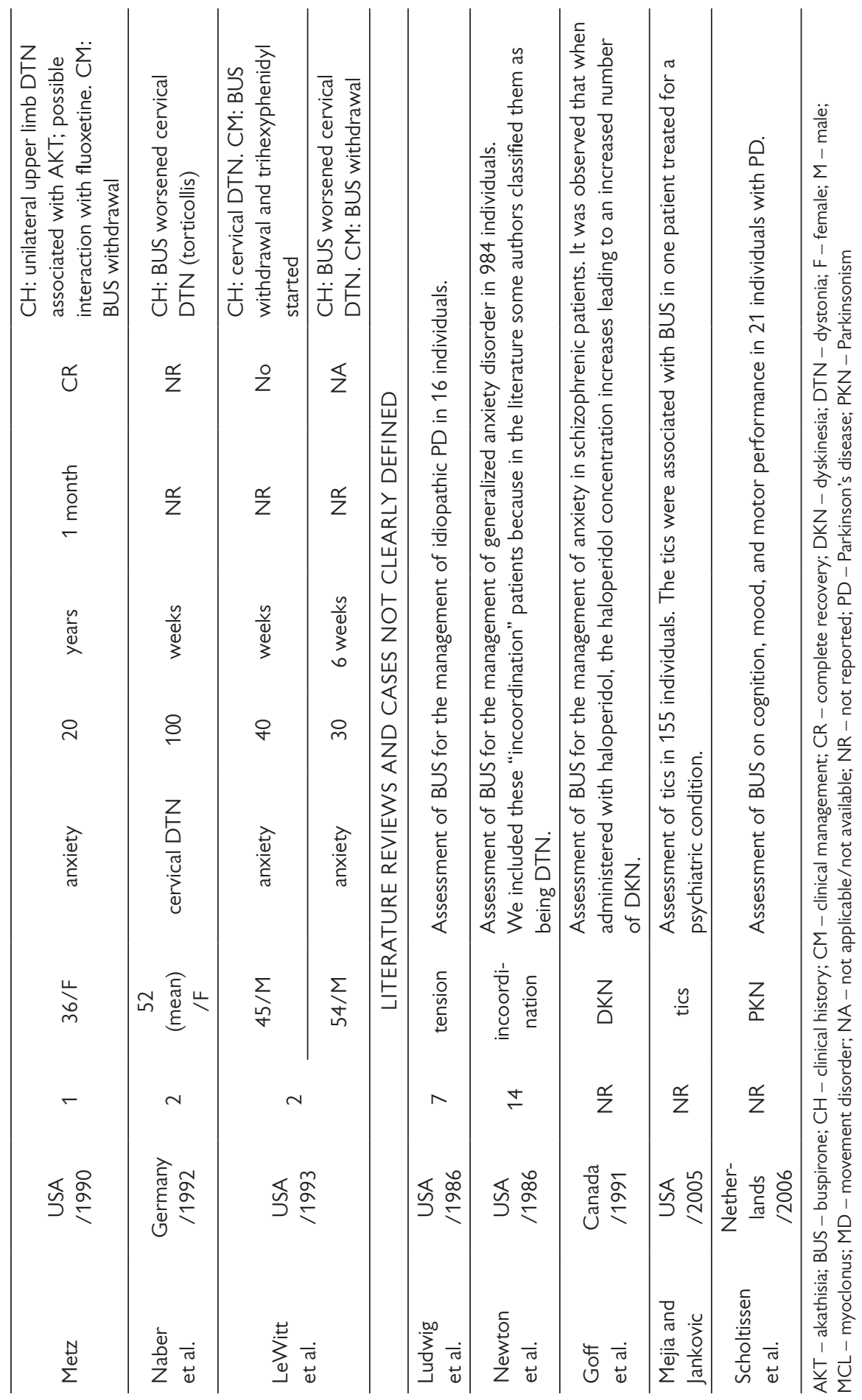



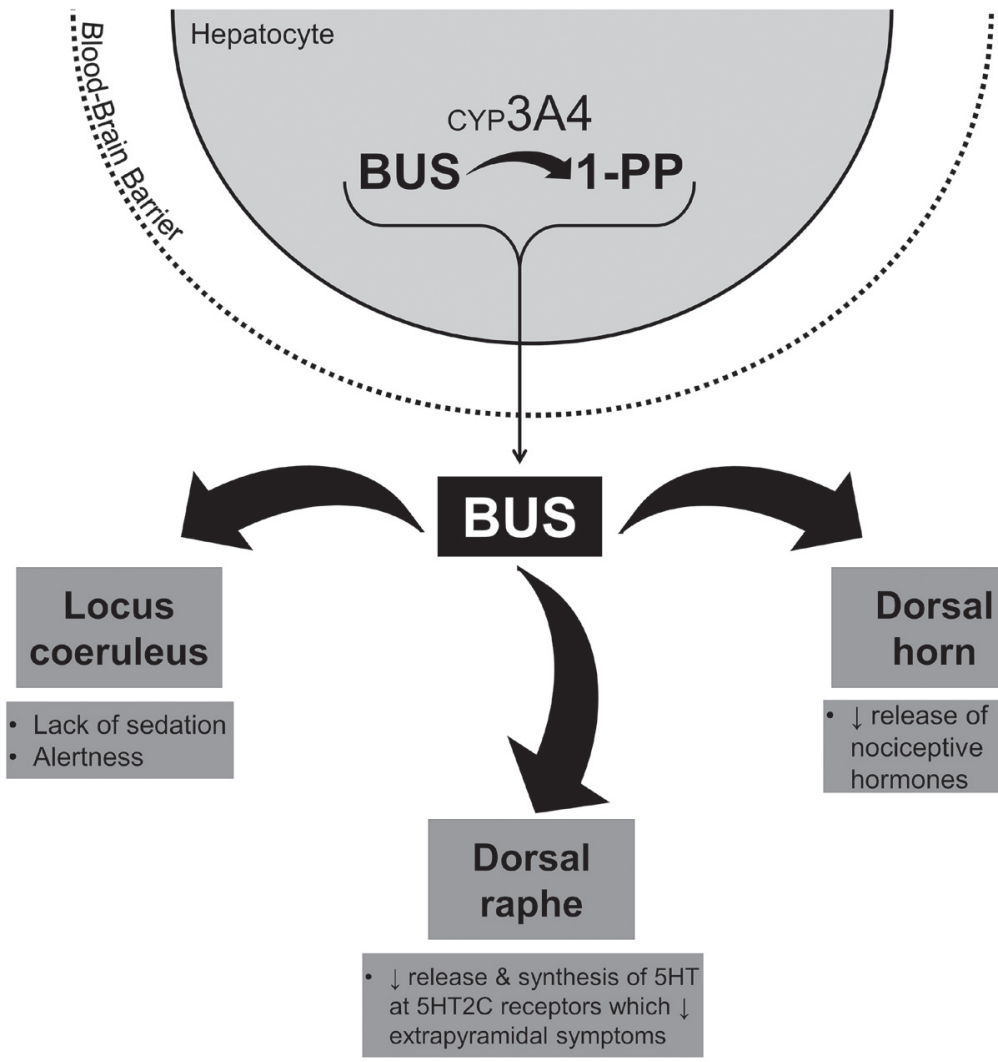

Figure 4 - Schematic diagram of buspirone (BUS) metabolism. After ingestion, BUS goes to the liver and is metabolized by CYP 3A4 to the 1-(2-pyrimidinyl) piperazine (1-PP), which is the major BUS metabolite. The locus coeruleus, dorsal raphe, and dorsal horn of the spinal cord are some of the sites of BUS action in the central nervous system. The arrows show a resume of the mechanisms to explain the BUS-use for neuropathic pain (dorsal horn) and dyskinesia (dorsal raphe).

general data, which could represent an important factor for the development of this abnormal movement (Smith and Baldessarini, 1980). By the way, one of the cases that did not have a full recovery was reported with DKN; to be more specific, the only among the DKN that had orofacial involvement (Strauss, 1988). Some individuals had a previous diagnosis of DKN, and when BUS was used, they had a worsening of DKN (Bonifati et al., 1994).

One of the hypotheses to explain the development of DKN involves the relationship of the serotonin, dopamine, and glutamate neurotransmitters in the striatum (Figure 5) (Floresco and Magyar, 2006; Shireen, 2016; Sokoloff and Le Foll, 2017; Atoji and Sarkar, 2019). Especially antipsychotics with dopamine D2 blockage can provoke an inflammatory process and release reactive oxygen species causing an abnormal adaptation of the striatal organization, and ultimately leading to 


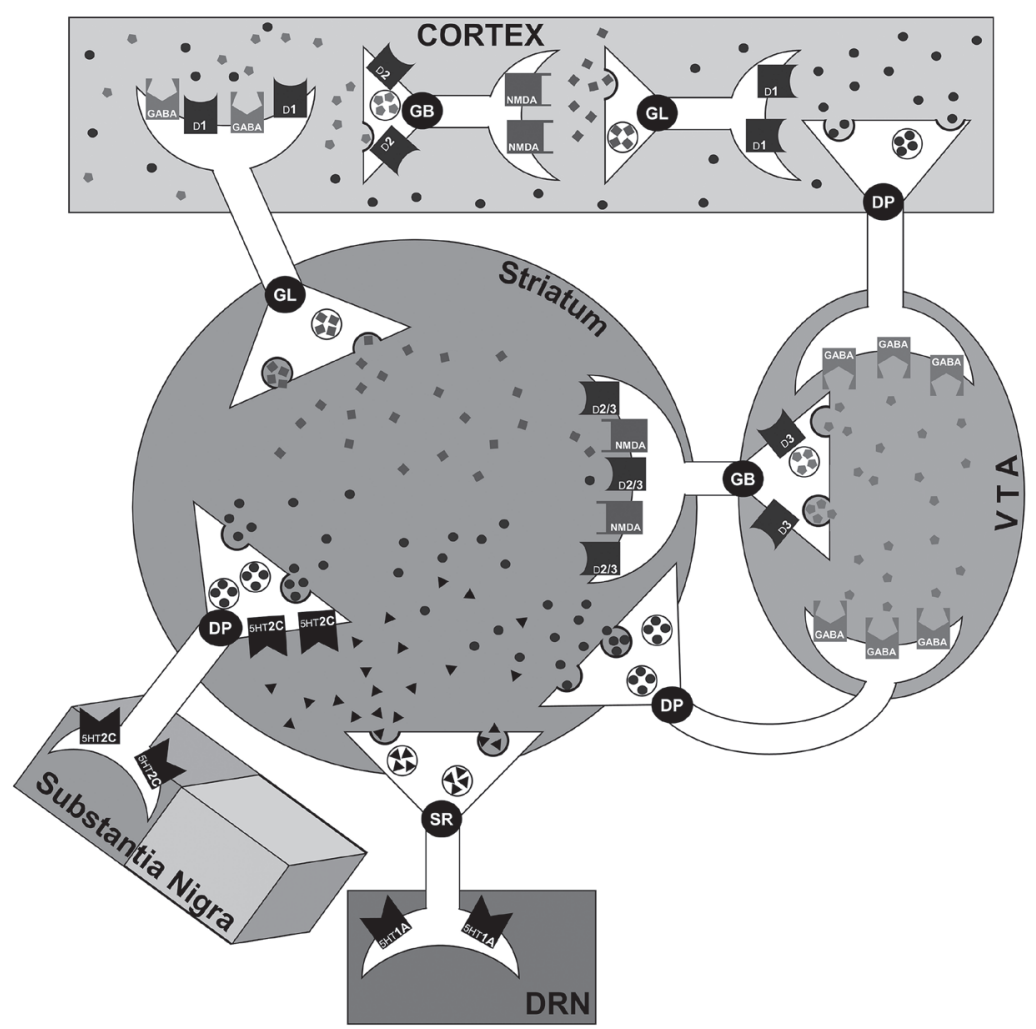

Figure 5 - Schematic diagram of the pathophysiological mechanism of antipsychotic-induced extrapyramidal symptoms (EPS) with serotoninergic modulation. Current antipsychotics act at D2/3 receptors, in which the D2 blockage may cause EPS and disbalance glutamate/GABA in the cortex leading to interference in taskdependent neuronal activities such as decision-making. D3 receptor antagonists (F17464) regulate dopamine (DA) neurotransmission in the ventral tegmental area (VTA) contributing to the normalization of DA release in the prefrontal cortex. 5HT1A receptor agonists (buspirone and 8OHDPAT) inhibit the release and synthesis of $5 \mathrm{HT}$ at $5 \mathrm{HT} 2 \mathrm{C}$ receptors decreasing the dopaminergic activity. $5 \mathrm{HT} 2 \mathrm{~A} / 2 \mathrm{C}$ receptor antagonists (mianserin) free DA from the $5 H T$ modulation influence. Dopamine (D1, 2, 3), GABA (GABA), glutamate (NMDA), and serotonin (5HT1A, 2C) receptors. Dopaminergic (DP), GABAergic $(G B)$, glutamatergic $(G L)$, and serotoninergic (SR) neurons. DRN - dorsal raphe nucleus.

overactivation of the direct pathway (Lepping et al., 2011). With this background, the benefit of BUS for the management of DKN is due to the agonism of 5HT1A (coupled to the Gi protein and mediates inhibitory neurotransmission) that decrease the release and synthesis of serotonin; the serotonin concentration decrease causes a reduction of $5 \mathrm{HT} 2 \mathrm{C}$ (coupled to the Gq protein and mediates excitatory neurotransmission) activity, which reduces the release of dopamine (Shireen, 2016). We believe that in some older individuals BUS may cause a selective block of D2 more than the agonism in 5HT2A can hold. This assumption is plausible in the cases 
reported and is supported by the relative longer movement disorder onset time when compared to general data.

\section{Akathisia (AKT)}

The AKT patients were younger than the mean data and all the subjects were males. The most frequently management was BUS withdrawal; in some reports, benzodiazepines were started (Rock, 1990). The BUS re-challenge was attempted in two cases, but in both the AKT reappeared earlier than in the first episode (Patterson, 1988; Rock, 1990). In the majority of the reports, the patients had previously used antipsychotics, so it may be a predisposition factor for the development of AKT (Jann et al., 1990). Poyurovsky and Weizman (1997) did an open-label study to investigate BUS for the treatment of acute-neuroleptic induced akathisia in 10 individuals; the therapeutic response was an improvement in 2 , worsening 2, unchanged 6 .

We hypothesized that the BUS-induced AKT is probably related to the noradrenergic neurotransmission. The 1-PP metabolite strongly interacts with the adrenergic $\alpha 2 \mathrm{~A}$ receptors leading to the disinhibition of the central noradrenergic system (Engberg, 1989). This can be supported by studies with animal models, which showed that noradrenaline causes the release of dopamine in the orbitofrontal cortex leading to the dopamine receptor D1 (coupled to the Gs protein and mediates excitatory neurotransmission) hyperactivation inducing AKT symptoms (Hurd et al., 2001; Dalley et al., 2008).

\section{Myoclonus (MCL)}

The individuals were younger, the BUS-dose were lower, and the time of movement disorder onset was shorter than the in general population. The management was drug withdrawal; benzodiazepines were also started (Ritchie et al., 1988). The presentation was apparently multifocal. The source cannot be characterized due to insufficient clinical features and the absence of electrodiagnostic studies, but we believe that was cortical origin because the use of BUS worsened MCL epileptic patients (Pranzatelli et al., 1993; Caviness and Brown, 2004). This abnormal movement was found in association with other drugs such as fluoxetine and trazodone, as a result, maybe the MCL was part of serotonin syndrome (Ables and Nagubilli, 2010).

$\mathrm{MCL}$ has been already associated with the deficiency and increase of serotonin (Jiménez-Jiménez et al., 2004). This is presupposed because in some individuals the use of drugs that increase the serotonin concentration like selective serotonin reuptake inhibitors showed a reduced frequency of jerks, but in other cases, the enhanced serotonin syndrome caused the increase of the frequency (GiménezRoldán et al., 1988). An important fact is that the interaction between serotonin 5-HT1A and 5-HT2 receptors is necessary to induce MCL (Klawans et al., 1973); both receptors are involved with BUS (Taylor, 1988). 


\section{Parkinsonism (PKN)}

In almost all the PKN cases, the patients had a previous diagnosis of Parkinson's disease (PD), and when BUS was tried the bradykinesia significantly worsened (Hammerstad et al., 1986; Kleedorfer et al., 1991). The management was BUS withdrawal. In only one patient without a movement disorder, the BUS caused the occurrence of PKN (Clay and Adams, 2003). The most interesting finding was that the BUS-doses related to this abnormal movement were about twice the average. One possible explanation for the BUS-induced PKN is the blockage of dopaminergic receptors, but the agonism to the serotoninergic neurotransmission leading to a decrease of dopamine also can contribute (López-Sendón et al., 2013). Therefore, we believe that in the patients with the previous diagnosis of PD probably predominated the dopamine block, and in the patients without a movement disorder the serotoninergic pathway. This can be supported by the BUS Ki values, time of movement disorder onset, and alteration in the dopaminergic striatum throughout the time in PD (Taylor, 1988; Zhai et al., 2018).

\section{Dystonia (DTN)}

The presentation was usually focal, such as a cervical and unilateral upper limb. It manifested more frequently in females (1:2), and this feature is similar to the studies of drug-induced DTN (Swett, 1975; Jiménez-Jiménez et al., 1997). The BUS-dose was slightly higher than in the general data. A characteristic feature that differs from the literature data is the time from BUS start to the DTN onset which was the highest among the BUS-associated movement disorders, while in the majority of the drug-induced DTN the time was relatively short (Jiménez-Jiménez et al., 1997).

Boylan (1990) reported the first case of DTN and three hypotheses were proposed to the development of this abnormal movement. First, Boylan (1990) suggested that the DTN occurred due to the antagonism of dopamine receptors, which is a possible explanation for all the extrapyramidal symptoms (EPS) associated with this drug if we believe that all of them were predisposed due to a higher affinity to dopaminergic instead of serotoninergic receptors by BUS (McMillen et al., 1983). Second, Jansen (1991) proposed that the BUS-induced DTN was due to the interaction of BUS with sigma $(\sigma)$ receptors; one important drawback to this assumption is that in animal studies the interaction with this receptor did not cause any abnormal movement, instead the serotonin receptors showed some influence (Paquette et al., 2009; Mohajjel Nayebi and Sheidaei, 2010). Third, Jiménez-Jiménez (1991) assumed that due to the higher affinity to serotonin receptors the cause was related to the increase of serotonin. We believe that the third mechanism is the most probable in the individuals reported and some facts in rat and monkey models can support this hypothesis: serotonin reuptake inhibitors can themselves induce EPS (Korsgaard et al., 1985); antipsychotic-induced EPS is worsened by the increase of serotonin concentration (Carter and Pycock, 1977); the antagonism of serotonin receptors can alleviate DTN (Richter and Löscher, 1995). 


\section{Conclusion}

In summary, movement disorders (MD) associated with BUS (buspirone) administration were encountered in descending order of frequency: dyskinesia, akathisia, myoclonus, Parkinsonism, tics, and dystonia. The Ki values of BUS may explain the mechanistic receptor preference for the occurrence of these disorders. In this context, BUS-induced akathisia is probably related to norepinephrine; myoclonus and dystonia are related to serotonin; dyskinesia and Parkinsonism to the dopamineserotoninergic hypothesis. The best management is probably the discontinuation of the offending agent in all cases of BUS-induced MD. It is worth mentioning that most of the reports not clearly describe the neurological examination, or the onset and recovery times of movement disorder.

\section{References}

Ables, A. Z., Nagubilli, R. (2010) Prevention, recognition, and management of serotonin syndrome. Am. Fam. Physician 81(9), 1139-1142.

American Psychiatric Association (2013) Diagnostic and Statistical Manual of Mental Disorders (DSM-5). American Psychiatric Publishing, Arlington.

Atoji, Y., Sarkar, S. (2019) Localization of AMPA, kainate, and NMDA receptor mRNAs in the pigeon cerebellum. J. Chem. Neuroanat. 98, 71-79.

Bonifati, V., Fabrizio, E., Cipriani, R., Vanacore, N., Meco, G. (1994) Buspirone in levodopa-induced dyskinesias. Clin. Neuropharmacol. 17(1), 73-82.

Boylan, K. (1990) Persistent dystonia associated with buspirone. Neurology 40(12), 1904.

Bristol-Myers Squibb Company (2001) BuSpar ${ }^{\circledR}$. Available at: https://www.accessdata.fda.gov/drugsatfda _docs/label/2001/18731s39s45lbl.pdf

Brody, D., Adler, L. A., Kim, T., Angrist, B., Rotrosen, J. (1990) Effects of buspirone in seven schizophrenic subjects. J. Clin. Psychopharmacol. 10(1), 68-69.

Carter, C. J., Pycock, C. J. (1977) Possible importance of 5-hydroxytryptamine in neuroleptic-induced catalepsy in rats [proceedings]. Br. J. Pharmacol. 60(2), 267P-268P.

Caviness, J. N., Brown, P. (2004) Myoclonus: Current concepts and recent advances. Lancet Neurol. 3(10), 598-607.

Clay, P. G., Adams, M. M. (2003) Pseudo-Parkinson disease secondary to ritonavir-buspirone interaction. Ann. Pharmacother. 37(2), 202-205.

ClinCalc (2019) Top 300 Drugs. Available at: https://clincalc.com/DrugStats/Top300Drugs.aspx

Coulter, D. M., Pillans, P. I. (1995) Fluoxetine and extrapyramidal side effects. Am. J. Psychiatry 152(1), $122-125$.

Dalley, J. W., Mar, A. C., Economidou, D., Robbins, T. W. (2008) Neurobehavioral mechanisms of impulsivity: Fronto-striatal systems and functional neurochemistry. Pharmacol. Biochem. Behav. 90(2), 250-260.

Eison, A. S., Temple, D. L. Jr. (1986) Buspirone: review of its pharmacology and current perspectives on its mechanism of action. Am. J. Med. 80(3B), 1-9.

Engberg, G. (1989) A metabolite of buspirone increases locus coeruleus activity via alpha 2-receptor blockade. J. Neural Transm. 76(2), 91-98.

Floresco, S. B., Magyar, O. (2006) Mesocortical dopamine modulation of executive functions: beyond working memory. Psychopharmacology (Berl.) 188(4), 567-585.

Giménez-Roldán, S., Mateo, D., Muradas, V., De Yebenes, J. G. (1988) Clinical, biochemical, and pharmacological observation in a patient with postasphyxic myoclonus: association to serotonin hyperactivity. Clin. Neuropharmacol. 11(2), 151-160. 
Goff, D. C., Midha, K. K., Brotman, A. W., McCormick, S., Waites, M., Amico, E. T. (1991) An open trial of buspirone added to neuroleptics in schizophrenic patients. J. Clin. Psychopharmacol. 11(3), 193-197.

Goldberg, R. J., Huk, M. (1992) Serotonin syndrome from trazodone and buspirone. Psychosomatics 33(2), 235-236.

Griffith, J. D., Jasinski, D. R., Casten, G. P., McKinney, G. R. (1986) Investigation of the abuse liability of buspirone in alcohol-dependent patients. Am. J. Med. 80(3B), 30-35.

Haleem, D. J., Nawaz, S., Salman, T. (2018) Dose related effects of buspirone on pain, learning/memory and food intake. Regul. Toxicol. Pharmacol. 99, 182-190.

Hammerstad, J. P., Carter, J., Nutt, J. G., Casten, G. C., Shrotriya, R. C., Alms, D. R., Temple, D. (1986) Buspirone in Parkinson's disease. Clin. Neuropharmacol. 9(6), 556-560.

Howland, R. H. (2015) Buspirone: back to the future. J. Psychosoc. Nurs. Ment. Health Serv. 53(11), 21-24. Hurd, Y. L., Suzuki, M., Sedvall, G. C. (2001) D1 and D2 dopamine receptor mRNA expression in whole hemisphere sections of the human brain. J. Chem. Neuroanat. 22(1-2), 127-137.

Jankovic, J., Tolosa, E. (2007) Parkinson's Disease and Movement Disorders. Lippincott Williams and Wilkins, Philadelphia.

Jann, M. W., Froemming, J. H., Borison, R. L. (1990) Movement disorders and new azapirone anxiolytic drugs. J. Am. Board Fam. Pract. 3(2), 111-119.

Jansen, K. L. (1991) Buspirone and dystonia. Neurology 41(11), 1850, correspondence. Jiménez-Jiménez, F. J. (1991) Buspirone and dystonia. Neurology 41(11), 1850, correspondence.

Jiménez-Jiménez, F. J., Garcia-Ruiz, P. J., Molina, J. A. (1997) Drug-induced movement disorders. Drug Saf. 16(3), 180-204.

Jiménez-Jiménez, F. J., Puertas, I., de Toledo-Heras, M. (2004) Drug-induced myoclonus: Frequency, mechanisms and management. CNS Drugs 18(2), 93-104.

Klawans, H. L. Jr., Goetz, C., Weiner, W. J. (1973) 5-hydroxytryptophan-induced myoclonus in guinea pigs and the possible role of serotonin in infantile myoclonus. Neurology 23(11), 1234-1240.

Kleedorfer, B., Lees, A. J., Stern, G. M. (1991) Buspirone in the treatment of levodopa induced dyskinesias. J. Neurol. Neurosurg. Psychiatry 54(4), 376-377.

Korsgaard, S., Gerlach, J., Christensson, E. (1985) Behavioral aspects of serotonin-dopamine interaction in the monkey. Eur. J. Pharmacol. 118(3), 245-252.

Lepping, P., Delieu, J., Mellor, R., Williams, J. H. H., Hudson, P. R., Hunter-Lavin, C. (2011) Antipsychotic medication and oxidative cell stress: a systematic review. J. Clin. Psychiatry 72(3), 273-285.

LeWitt, P. A., Walters, A., Hening, W., McHale, D. (1993) Persistent movement disorders induced by buspirone. Mov. Disord. 8(3), 331-334.

Liegghio, N. E., Yeragani, V. K., Moore, N. C. (1988) Buspirone-induced jitteriness in three patients with panic disorder and one patient with generalized anxiety disorder. J. Clin. Psychiatry 49(4), 165-166.

Loane, C., Politis, M. (2012) Buspirone: what is it all about? Brain Res. 1461, 111-118.

López-Sendón, J., Mena, M. A., de Yébenes, J. G. (2013) Drug-induced Parkinsonism. Expert Opin. Drug Saf. 12(4), 487-496.

Ludwig, C. L., Weinberger, D. R., Bruno, G., Gillespie, M., Bakker, K., LeWitt, P. A., Chase, T. N. (1986) Buspirone, Parkinson's disease, and the locus ceruleus. Clin. Neuropharmacol. 9(4), 373-378.

Lydiard, R. (1989) Buspirone revisited. J. Clin. Psychiatry 50(8), 308-308.

Manos, G. H. (2000) Possible serotonin syndrome associated with buspirone added to fluoxetine. Ann. Pharmacother. 34(7-8), 871-874.

McMillen, B. A., Matthews, R. T., Sanghera, M. K., Shepard, P. D., German, D. C. (1983) Dopamine receptor antagonism by the novel antianxiety drug, buspirone. J. Neurosci. 3(4), 733-738.

Mejia, N. I., Jankovic, J. (2005) Secondary tics and tourettism. Braz. J. Psychiatry 27(1), 11-17. 
Metz, A. (1990) Interaction between fluoxetine and buspirone. Can. J. Psychiatry 35(8), 722-723.

Mohajjel Nayebi, A. A., Sheidaei, H. (2010) Buspirone improves haloperidol-induced Parkinson disease in mice through 5-HT(1A) recaptors. Daru 18(1), 41-45.

Naber, D., Weinberger, D. R., Gillespie, M., Chase, T. N. (1992) Failure of buspirone and verapamil to improve spasmodic torticollis. J. Neuropsychiatry Clin. Neurosci. 4(1), 82-84.

Naranjo, C. A., Busto, U., Sellers, E. M., Sandor, P., Ruiz, I., Roberts, E. A., Janecek, E., Domecq, C., Greenblatt, D. J. (1981) A method for estimating the probability of adverse drug reactions. Clin. Pharmacol. Ther. 30(2), 239-245.

Newton, R. E., Marunycz, J. D., Alderdice, M. T., Napoliello, M. J. (1986) Review of the side-effect profile of buspirone. Am. J. Med. 80(3B), 17-21.

Paquette, M. A., Foley, K., Brudney, E. G., Meshul, C. K., Johnson, S. W., Berger, S. P. (2009) The sigma-1 antagonist BMY-14802 inhibits L-DOPA-induced abnormal involuntary movements by a WAY-100635 -sensitive mechanism. Psychopharmacology (Berl.) 204(4), 743-754.

Patterson, J. F. (1988) Akathisia associated with buspirone. J. Clin. Psychopharmacol. 8(4), 296-297.

Poyurovsky, M., Weizman, A. (1997) Serotonergic agents in the treatment of acute neuroleptic-induced akathisia: open-label study of buspirone and mianserin. Int. Clin. Psychopharmacol. 12(5), 263-268.

Pranzatelli, M. R., Franz, D., Tate, E., Martens, J. M. (1993) Buspirone in progressive myoclonus epilepsy. J. Neurol. Neurosurg. Psychiatry 56(1), 114-115.

Richter, A., Löscher, W. (1995) Behavioural response to pharmacologic manipulation of serotonin receptors in the genetically dystonic hamster. Pharmacol. Biochem. Behav. 52(4), 655-665.

Ritchie, E. C., Bridenbaugh, R. H., Jabbari, B. (1988) Acute generalized myoclonus following buspirone administration. J. Clin. Psychiatry 49(6), 242-243.

Rock, N. L. (1990) Possible adverse effects of buspirone when used with other psychotropic drugs. J. Clin. Psychopharmacol. 10(5), 380-381.

Scholtissen, B., Verhey, F. R. J., Adam, J. J., Weber, W., Leentjens, A. F. G. (2006) Challenging the serotonergic system in Parkinson disease patients: Effects on cognition, mood, and motor performance. Clin. Neuropharmacol. 29(5), 276-285.

Shireen, E. (2016) Experimental treatment of antipsychotic-induced movement disorders. J. Exp. Pharmacol. 8, 1-10.

Smith, J. M., Baldessarini, R. J. (1980) Changes in prevalence, severity, and recovery in tardive dyskinesia with age. Arch. Gen. Psychiatry 37(12), 1368-1373.

Sokoloff, P., Le Foll, B. (2017) The dopamine D3 receptor, a quarter century later. Eur. J. Neurosci. 45(1), 2-19.

Strauss, A. (1988) Oral dyskinesia associated with buspirone use in an elderly woman. J. Clin. Psychiatry 49(8), 322-323.

Swett, C. Jr. (1975) Drug-induced dystonia. Am. J. Psychiatry 132(5), 532-534.

Taylor, D. P. (1988) Buspirone, a new approach to the treatment of anxiety. FASEB J. 2(9), 2445-2452.

Tompins, E., Clemento, A., Taylor, D. P., Perhach, J. (1980) Inhibition of aggressive behavior in rhesus monkeys by buspirone. Res. Commun. Psychol. Psychiatr. Behav. 5(4), 337-352.

Wilson, T. K., Tripp, J. (2019) Buspirone. StatPearls [Internet], StatPearls Publishing, Treasure Island.

Zhai, S., Tanimura, A., Graves, S. M., Shen, W., Surmeier, D. J. (2018) Striatal synapses, circuits, and Parkinson's disease. Curr. Opin. Neurobiol. 48, 9-16. 